\title{
Discovery of Highly Potent and Selective Bruton's Tyrosine Kinase Inhibitors: Pyridazinone Analogs with Improved Metabolic Stability
}

\author{
Wendy B. Young*a, James Barbosa ${ }^{\mathrm{b}}$, Peter Blomgren ${ }^{\mathrm{b}}$, Meire C. Bremer ${ }^{\mathrm{a}}$, James J. Crawford ${ }^{\mathrm{a}}$, Donna \\ Dambach $^{\mathrm{a}}$, Charles Eigenbrot ${ }^{\mathrm{a}}$, Steve Gallion ${ }^{\mathrm{c}}$, Adam R. Johnson ${ }^{\mathrm{a}}$, Jeffrey E. Kropf ${ }^{\mathrm{b}}$, Seung H. Lee ${ }^{\mathrm{b}}$, \\ Lichuan Liu $^{\mathrm{a}}$, Joseph W. Lubach ${ }^{\mathrm{a}}$, Jen Macaluso ${ }^{\mathrm{b}}$, Pat Maciejewski ${ }^{\mathrm{b}}$, Scott A. Mitchell ${ }^{\mathrm{b}}$, Daniel F. Ortwine \\ ${ }^{a}$, Julie Di Paolo ${ }^{\mathrm{b}}$, Karin Reif ${ }^{\mathrm{a}}$, Heleen Scheerens ${ }^{\mathrm{a}}$, Aaron Schmitt ${ }^{\mathrm{b}}$, Xiaojing Wang ${ }^{\mathrm{a}}$, Harvey Wong ${ }^{\mathrm{a}}$, Jin- \\ Ming Xiong ${ }^{\mathrm{b}}$, Jianjun $\mathrm{Xu}^{\mathrm{b}}$, Christine Yu, Zhongdong Zhao ${ }^{\mathrm{b}}$ and Kevin S. Currie ${ }^{\mathrm{b}}$
}

\footnotetext{
${ }^{a}$ Genentech, 1 DNA Way, South San Francisco, CA 94080

${ }^{b}$ Gilead Sciences, 36 East Industrial Rd., Branford, CT 06405

${ }^{c}$ St. Andrews Circle, Wallingford, CT 06492
}

\section{ARTICLE INFO}

\section{ABSTRACT}

Article history:

Received

Revised

Accepted

Available online

\section{Keywords:}

Kinase inhibitor, Bruton's tyrosine kinase, Btk,

Rheumatoid arthritis, pyridazinone
BTK inhibitor GDC-0834 (1) was found to be rapidly metabolized in human studies, resulting in a suspension of clinical trials. The primary route of metabolism was through cleavage of the acyclic amide bond connecting the terminal tetrahydrobenzothiophene with the central linker aryl ring. SAR studies were focused on reducing metabolic cleavage of this amide, and resulted in the identification of several central aryl linker substituents that conferred improved stability. The most promising substituted aryl linkers were then incorporated into an optimized pyridazinone scaffold, resulting in the identification of lead analog 23, possessing improved potency, metabolic stability and preclinical properties.
Bruton's tyrosine kinase (BTK) plays a critical role in the development, differentiation and proliferation of B-lineage cells, making it an attractive target for the treatment of immunological disorders such as rheumatoid arthritis (RA), lupus, and multiple sclerosis (MS) ${ }^{1-4}$, as well as B-cell malignancies. ${ }^{5}$ As outlined in the preceding papers, ${ }^{6-7}$ we identified GDC-0834 (1) as a highly potent and selective inhibitor of BTK with acceptable pharmacokinetic (PK) and safety profiles in preclinical species.

In a clinical trial, $\mathbf{1}$ was found to be labile at the acyclic amide bond resulting in rapid metabolism. ${ }^{7}$ The major metabolic liability was identified to be cleavage of the primary amide to liberate the corresponding aniline and acid by-products (Figure 1), making 1 unsuitable for further clinical developmentdue to the low exposure of parent drug. This cleavage was determined to result from a non-CYP mediated process that was more prevalent in man than preclinical species such as mouse, rat, dog, and monkey. Herein, we outline the discovery of second generation pyridazin-3(2H)-one analogs with improved non-cyp mediated metabolic stability, and which maintained the potency, high target selectivity, and favorable safety profile of the original series.

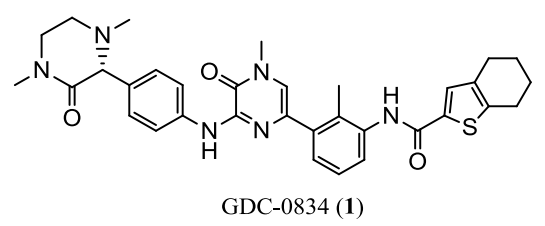

Initially, we pursued two strategies to improve the metabolic stability of the lead compound $\mathbf{1}$. The first was to remove the labile acyclic amide entirely and replace it with common isosteres or alternate linkers such as $-\mathrm{NHSO}_{2^{-}},-\mathrm{SO}_{2} \mathrm{NH}-,-\mathrm{NHCHCF}_{3}{ }^{-}$, $\mathrm{CONH}-$, and -NMeCO-. Unfortunately, all such modifications on the GDC-0834 (1) scaffold or earlier tool molecules produced analogs with dramatically reduced potency, likely due to a change in the ligand conformation or disrupting the interaction with $\mathrm{K} 430,{ }^{6}$ so this endeavor was quickly abandoned. The second strategy involved adding steric bulk around the acyclic amide to potentially hinder amide cleavage. At the time of these medicinal chemistry explorations we did not know what enzyme was responsible for cleaving the amide bond, so a structure-based design approach could not be applied. ${ }^{8}$ Therefore, we synthesized a range of analogs 
with mono- or bis- substitution ortho to the amide moiety linking the central aryl to the 4,5,6,7-tetrahydrobenzo[b]thiophene group (Table 1) to probe steric and electronic influences on this undesired metabolic pathway. The goal was to find an analog closely related to 1 that maintained many of its positive attributes (potency, selectivity, safety profile), but was significantly less prone to cleavage at the amide bond.

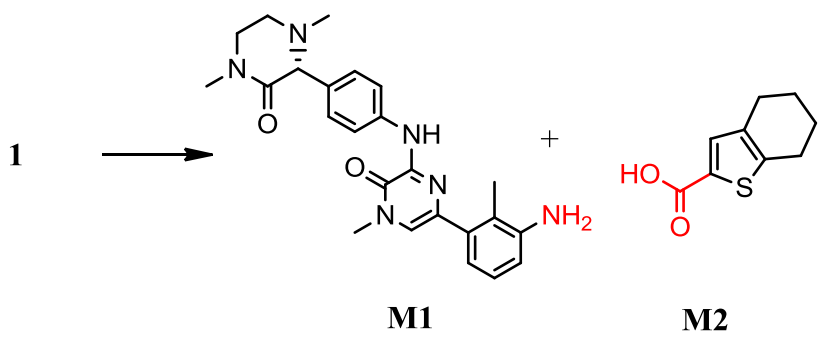

Figure 1: The major metabolic pathway of GDC-0834 (1) in human was determined to be amide cleavage to liberate byproducts $\mathbf{M 1}$ and $\mathbf{M} 2$.

For synthetic expediency, we chose to generate the majority of target compounds as racemic mixtures at the attachment point of the piperazinone to the aryl group and then isolate the enantiomers of selected compounds using supercritical fluid chromatography (SFC). In a few cases, we synthesized the individual $(R)$ enantiomer directly as the required chiral intermediate was available from the synthesis of GDC-0834. ${ }^{6}$ In the case of $\mathbf{1 5}$, we were able to assign the $(\mathrm{S})$ configuration after $16(\mathrm{R})$ was unambiguously synthesized and a racemic mixture of $\mathbf{1 5}$ and $\mathbf{1 6}$ was resolved by SFC. The sense of chirality of each analog is noted in Table 1. Inhibition of the target enzyme (BTK) was assessed and, for later examples (Tables 2 and 3), the downstream effect on anti-IgM-stimulated cell surface CD86 expression on B-cells. Cleavage of GDC0834's amide bond was determined to be a non-CYP mediated metabolic reaction based on its lack of NADPH dependence. In addition, metabolites associated with amide bond cleavage were absent in in vitro incubations with purified CYPS serving to confirm that CYPS were not involved. Therefore, metabolic stability was monitored using in vitro human liver microsomes in the absence of NADPH since the original amide cleavage was determined not to be CYP-mediated and thus NADPH independent. ${ }^{7}$ Performing the experiment in this manner produced predominantly by-products of amide cleavage $(e . g$. amines and acids, as depicted in Figure 1) and proved useful to track the SAR of this undesired metabolism. Metabolism ID studies were run after incubation with human liver microsomes (in the absence of NADPH) to confirm by HPLC/MS that the by-products were predominantly from amide cleavage. Metabolism results are shown in Table 1 as categories (stable, moderate, labile) for ease of comparison. Full in vitro predicted hepatic clearance details can be found in the Supplementary Materials.

The baseline compound (2), lacking substitution at the 2- and 6- position, was labile at the amide bond. Mono ortho substituted analogs 1, 3, and 4 were also highly labile, indicating that steric bulk at the 2-position did not deter amide cleavage. In contrast, substitution at the 6-position, as in compounds 5-8, did inhibit cleavage and displayed improved stability when compared to $\mathbf{1}$. Not surprisingly, compounds with 2,6-disubstitution (9-21) were also more stable than $\mathbf{1}$. Biochemical potencies of most analogs (except 5, 6, and 9) were within 4 -fold of $\mathbf{1}$, showing that this region could tolerate a variety of substituents. Pleasingly, several analogs (isomeric pairs $\mathbf{7 / 8}, \mathbf{1 0} / \mathbf{1 1}, \mathbf{1 3} / \mathbf{1 4}$, and 15/16) had improved amide stability and potency comparable to GDC-0834. Unfortunately, all these analogs had minimal to no oral bioavailability in rats and hence were not progressed further.

Table 1. Enzyme activity and in vitro stability SAR of BTK inhibitors with central aryl group modifications

[

\begin{tabular}{|c|c|c|c|c|c|}
\hline CMPD & $\mathbf{X}$ & $\mathbf{Y}$ & Conf $^{a}$ & $\begin{array}{c}\text { BTK } \\
\mathrm{IC}_{50}(\mathrm{nM})\end{array}$ & HLM (-) ${ }^{\mathrm{b}, \mathrm{c}, \mathrm{d}, \mathrm{e}}$ \\
\hline 1 & $\mathrm{Me}$ & $\mathrm{H}$ & $\mathrm{R}$ & 14 & $\mathrm{~L}$ \\
\hline 2 & $\mathrm{H}$ & $\mathrm{H}$ & Rac & 6 & $\mathrm{~L}$ \\
\hline 3 & $\mathrm{~F}$ & $\mathrm{H}$ & Rac & 8 & $\mathrm{~L}$ \\
\hline 4 & $\mathrm{Cl}$ & $\mathrm{H}$ & Rac & 6 & $\mathrm{~L}$ \\
\hline 5 & $\mathrm{H}$ & $\mathrm{CN}$ & Rac & 1400 & $\mathrm{~S}$ \\
\hline 6 & $\mathrm{H}$ & $\mathrm{Cl}$ & Rac & 61 & $M$ \\
\hline 7 & $\mathrm{H}$ & $\mathrm{F}$ & $\mathrm{U}$ & 24 & $S$ \\
\hline 8 & $\mathrm{H}$ & $\mathrm{F}$ & $\mathrm{U}$ & 9 & $M$ \\
\hline 9 & $\mathrm{Me}$ & $\mathrm{Cl}$ & Rac & 88 & $\mathrm{M}$ \\
\hline 10 & $\mathrm{~F}$ & $\mathrm{~F}$ & $\mathrm{U}$ & 4 & $\mathrm{M}$ \\
\hline 11 & $\mathrm{~F}$ & $\mathrm{~F}$ & $\mathrm{U}$ & 3 & $M$ \\
\hline 12 & $\mathrm{Cl}$ & $\mathrm{Cl}$ & Rac & 15 & $\mathrm{M}$ \\
\hline 13 & $\mathrm{Me}$ & $\mathrm{F}$ & $\mathrm{U}$ & 17 & $\mathrm{M}$ \\
\hline 14 & $\mathrm{Me}$ & $\mathrm{F}$ & $\mathrm{U}$ & 14 & $\mathrm{~S}$ \\
\hline 15 & $\mathrm{~F}$ & $\mathrm{Me}$ & $S$ & 6 & $S$ \\
\hline 16 & $\mathrm{~F}$ & $\mathrm{Me}$ & $\mathrm{R}$ & 6 & $S$ \\
\hline 17 & $F$ & $\mathrm{Cl}$ & $\mathrm{U}$ & 23 & $S$ \\
\hline 18 & $\mathrm{~F}$ & $\mathrm{Cl}$ & $\mathrm{U}$ & 9 & $S$ \\
\hline 19 & $\mathrm{Cl}$ & $\mathrm{Me}$ & $\mathrm{U}$ & 39 & $S$ \\
\hline 20 & $\mathrm{Cl}$ & $\mathrm{Me}$ & $\mathrm{U}$ & 5 & $S$ \\
\hline 21 & $\mathrm{Me}$ & $\mathrm{Me}$ & Rac & 20 & $S$ \\
\hline
\end{tabular}

a) Configuration at the attachment point of the piperazinone to the aryl group: Rac (racemate); U (single stereoisomer unconfirmed stereochemistry); $\mathrm{R}$ ( $\mathrm{R}$ configuration); $\mathrm{S}$ (S configuration); b) assay conditions supplied in Supplementary Materials c) Human liver microsome stability assay run in the absence (-) of NADPH; d) Metabolic Clearance $(\mathrm{CL})$ values $(\mathrm{mL} / \mathrm{min} / \mathrm{kg})$ : S (Stable) $<6 ; \mathrm{M}$ (Moderate) $=6-15 ; \mathrm{L}$ (Labile) $>15$; e) The predicted hepatic clearance values are provided in the Supplementary Materials.

At this point, we abandoned the concept of identifying a close-in analog of $\mathbf{1}$ that would be candidate quality and instead chose to re-tool the scaffold. We had identified several aryl substitution patterns with potential to reduce cleavage of the amide bond that could be incorporated into a next round of designs. Along with continuing to probe aryl substitution, we turned our attention to probing additional interactions between the ligand and BTK protein to improve binding potency. We looked to modify the methylpyrazin- $2(1 \mathrm{H})$-one with alternate heterocycles that could offer another H-bonding opportunity with the protein. Amino-pyridazinones have been reported to be efficient kinase hinge binders 9 that have the potential to form three H-bonds with the hinge region. Additionally, from ongoing work in a related chemical series, ${ }^{10}$ we had discovered that a 5-methyl-4,5,6,7-tetrahydropyrazolo[1,5-a]pyrazine in the 
solvent exposed region improved biochemical potency over the dimethyl-2-piperazinone group within 1, and that oxidation of the tetrahydrobenzo[b]thiophene to a benzothiophene ring offered improved metabolic stability, in most analogs, as well. Thus, with these changes in mind, we constructed a series of second generation pyridazin-3(2H)-one analogs with selected compounds as outlined in Table 2.

Table 2: Potency and metabolic stability of central aryl ring substituted pyridazinone BTK inhibitors

\begin{tabular}{|c|c|c|c|c|c|c|}
\hline \multirow[b]{2}{*}{ CMPD } & \multirow[b]{2}{*}{$\mathbf{X}$} & \multirow[b]{2}{*}{$\mathbf{Y}$} & \multicolumn{2}{|c|}{$\mathrm{IC}_{50} \mathrm{nM}^{\mathrm{a}}$} & \multirow{2}{*}{$\underset{(-/+)^{\mathrm{a}, \mathrm{b}, \mathrm{d}, \mathrm{e}}}{\mathbf{\text { HLM }}}$} & \multirow[b]{2}{*}{$\underset{\mathrm{a}, \mathrm{c}, \mathrm{d}, \mathrm{e}}{\mathbf{H H E P}}$} \\
\hline & & & BTK & CD86 & & \\
\hline 22 & $\mathrm{Me}$ & $\mathrm{H}$ & 4 & 41 & $\mathrm{~L} / \mathrm{L}$ & -- \\
\hline 23 & $\mathrm{Me}$ & $\mathrm{F}$ & 3 & 91 & $\mathrm{M} / \mathrm{M}$ & S \\
\hline 24 & $\mathrm{~F}$ & $\mathrm{~F}$ & 1 & 18 & $--/ \mathrm{L}$ & $\mathrm{M}$ \\
\hline 25 & $\mathrm{Me}$ & $\mathrm{Me}$ & 20 & 387 & $\mathrm{~S} / \mathrm{L}$ & -- \\
\hline 26 & F & $\mathrm{Me}$ & 11 & 200 & $\mathrm{M} / \mathrm{M}$ & -- \\
\hline 27 & $\mathrm{H}$ & $\mathrm{F}$ & 10 & 50 & $\mathrm{~S} / \mathrm{L}$ & $\mathrm{L}$ \\
\hline
\end{tabular}

a) assay protocols in Supplementary Materials; b) HLM=human liver microsome stability assay run in the absence (-) and presence (+) of NADPH; c) hHEP = human liver hepatocyte stability; d) Metabolic CL values $(\mathrm{mL} / \mathrm{min} / \mathrm{kg}): \mathrm{S}$ (stable) $<6 ; \mathrm{M}$ (moderate) $=6-15$; L (labile) $>15$; e) The predicted hepatic clearance values are provided in the Supplementary Materials.

In this series, 22 represents a baseline compound with the central aryl ring maintaining the same substitution pattern at the 2- and 6- positions as the original lead $\mathbf{1}$. In comparison to $\mathbf{1}$, 22 offered a moderate improvement in BTK biochemical and cell potency $\left(1\right.$, BTK $\mathrm{IC}_{50}=14 \mathrm{nM}$; CD86 $\left.\mathrm{IC}_{50}=60 \mathrm{nM}\right)$ but no improvement in overall metabolic stability. We were pleased to find that when some of the preferred central aryl ring substituents explored in the pyrazinone series (Table 1) were applied to these new pyridazinones, improvements in metabolic stability were seen as compared to the baseline pyridazinone $\mathbf{2 2}$. All central aryl substituted analogs (23, 25-27) except $\mathbf{2 4}$, showed an improvement in metabolic stability in human liver microsomes in the absence of NADPH. Of these arylsubstituted analogs, only $\mathbf{2 3}$ and $\mathbf{2 6}$ offered moderate stability in liver microsomes in the presence of NADPH (as compared to 22). In addition, $\mathbf{2 3}$ was found to be stable in human liver hepatocytes. Thus, of all these compounds, $\mathbf{2 3}$ had the best overall profile with moderate stability in human liver microsomes (-/+NADPH), low clearance in human hepatocytes, and acceptable BTK biochemical and cell potency.

We next probed replacements of the benzothiophene group with isosteres and/or other aryl groups that we found suitable from earlier work. ${ }^{6}$ Key analogs are shown in Table 3. Azaanalogs of the benzothiophene, as in $\mathbf{2 8}$ and $\mathbf{2 9}$, dramatically decreased affinity for BTK, presumably due to incompatibility with the lipophilic nature of the binding pocket. Altering the aryl group to two of our earlier and more potent monosubstituted aromatic rings, ${ }^{6}$ as in $\mathbf{3 0}$ and $\mathbf{3 1}$, offered potent and moderately stable compounds. Unfortunately these compounds lacked oral bioavailability in rat. Thus, 23 was determined to be the preferred compound to progress.
Table 3: Potency and metabolic stability of $\mathrm{H} 3$-substituted pyridazinone BTK inhibitors

\begin{tabular}{|c|c|c|c|c|c|}
\hline \multirow{2}{*}{ CMPD } & \multirow{2}{*}{$\mathbf{X}$} & \multicolumn{2}{|c|}{$\mathrm{IC}_{50} \mathrm{nM}^{\mathrm{a}}$} & \multirow{2}{*}{$\begin{array}{c}\text { HLM } \\
(-/+)^{\mathrm{a}, \mathrm{b}, \mathrm{d}, \mathrm{e}}\end{array}$} & \multirow{2}{*}{$\underset{\mathrm{a}, \mathrm{c}, \mathrm{d}, \mathrm{e}}{\mathbf{H H E P}}$} \\
\hline & & BTK & CD86 & & \\
\hline 23 & & 3 & 91 & $\mathrm{M} / \mathrm{M}$ & S \\
\hline 28 & & 132 & 680 & $\mathrm{M} / \mathrm{M}$ & M \\
\hline 29 & & 103 & 740 & $\mathrm{M} / \mathrm{M}$ & -- \\
\hline 30 & & 4 & 54 & $\mathrm{M} / \mathrm{L}$ & M \\
\hline 31 & & 4 & 90 & $\mathrm{M} / \mathrm{M}$ & M \\
\hline
\end{tabular}

a) assay protocol in Supplementary Materials; b) human liver microsome stability assay run in the presence (+) and absence (-) of NADPH; c) hHEP $=$ human liver hepatocyte stability d) Metabolic CL values $(\mathrm{mL} / \mathrm{min} / \mathrm{kg}): \mathrm{S}$ (stable) <6; M (moderate) $=6-15 ; \mathrm{L}$ (labile) >15; e) The predicted hepatic clearance values are provided in the Supplementary Materials.

To assist in rationalizing the observed SAR and in the design of novel congeners, a 1.36- $\AA$ resolution crystal structure of $\mathbf{2 3}$ in complex with BTK was obtained (Figure 3a). Interestingly, although nearly every ring was modified from the original lead GDC-0834 (1), 23 had a near identical binding mode (Figure 3b). The pyridazinone carbonyl and attached anilinic NH form the expected acceptor/donor H-bonds with the backbone $\mathrm{NH}$ and carbonyl of M477, holding the core heterocycle in place. A third water-mediated H-bond is apparent between the pyridazinone NH moiety and E475. The pyridazinone imino ring nitrogen is adjacent to a water-filled cavity, and forms a water mediated $\mathrm{H}$-bond to $\mathrm{K} 430$. Thus, the polar face of the pyridazinone occupies a polar internal area of the BTK protein, contributing to the high binding affinity observed for this series. In a similar vein to GDC-0834, the acyclic amide is rotated $78^{\circ}$ out of plane relative to the linker phenyl, and its carbonyl accepts an H-bond from K430, although at an oblique angle. The benzothiophene ring occupies an induced fit hydrophobic site ("H3 site") formed by D521, N526, D539, L542, S543, and importantly, Y551 from the activation loop. This tyrosine moves $17 \AA$ from an observed apo orientation to encapsulate the terminal phenyl ring of the benzothiophene. ${ }^{3}$ Because $\mathbf{2 3}$ contains no freely rotatable bonds and thus has low entropy, this allows Y551 within the normally flexible activation loop to "discover" the inhibitor terminal phenyl ring and pack against it, effectively freezing the activation loop in an inactive conformation. This binding mode undoubtedly contributes to the exquisite sensitivity of this ring to substitution. The 5methyl-4,5,6,7-tetrahydropyrazolo[1,5-a]pyrazine largely extends into solvent, making contact with a portion of Y476. 
(a)

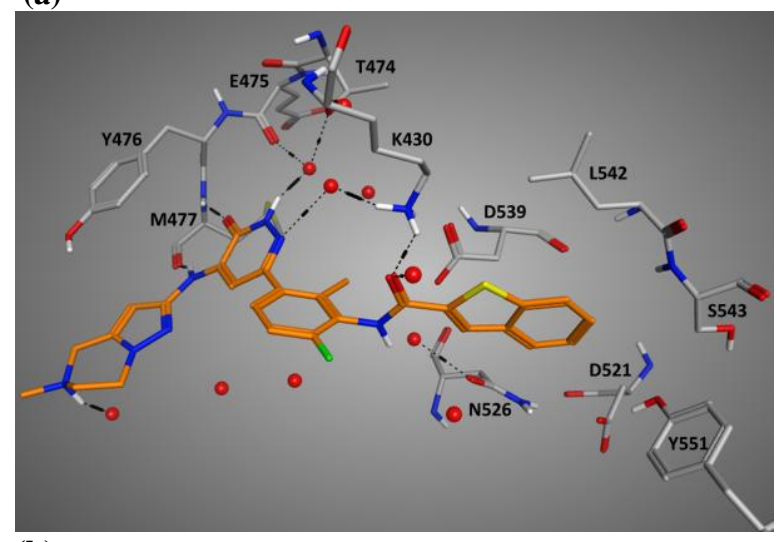

(b)

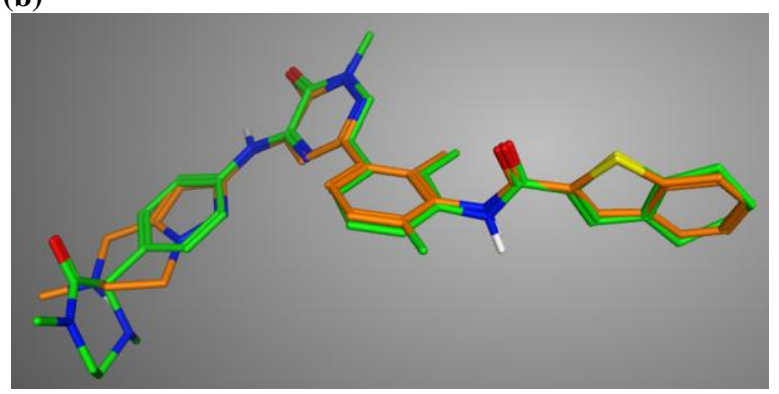

Figure 3. (a) Crystal structure of 23 complexed to BTK; (b) Superposition of GDC-0834 (green) and $\mathbf{2 3}$ (orange) from their protein/ligand $\mathrm{X}$-ray structures after aligning the proteins.

Importantly, 23 demonstrated excellent biochemical selectivity when screened at $1 \mathrm{uM}$ against a panel of 228 kinases in the SelectScreen ${ }^{\circledR}$ Kinase Profiling Services of Invitrogen-Life Technologies (Madison, USA), showing >50\% inhibition of the activity of only 6 kinases - BTK, BMX, TEC, FGR, MELK, and SRC (data in Supplementary Material). We obtained $\mathrm{IC}_{50}$ values for these kinases to increase the precision of the selectivity profile (as shown in Table 4). Compound 23 had greater than 300-fold selectivity for BTK versus FGR, SRC and MELK, thus providing a low risk of inhibiting these kinase targets. The margins of $\mathbf{2 3}$ against BMX and TEC were smaller, with only 5-fold and 77-fold selectivity, respectively. To our knowledge, there are no reports of clinical safety data associated with potent and selective inhibitors of BMX or TEC kinases to determine the risk of inhibiting these off-targets. However, existing non-clinical data related to such inhibition have not been cause for concern. ${ }^{11-14}$ In the case of TEC, ${ }^{14}$ inhibition of this protein may in fact have a beneficial effect as an anti-inflammatory agent.

Further profiling indicated that $\mathbf{2 3}$ had no significant offtarget activity when screened against a panel of 30 receptors (all $<35 \%$ at $10 \mathrm{uM}$ ). Only minimal inhibition of the hERG channel $(27 \%$ at $10 \mathrm{uM})$ was found, and $\mathbf{2 3}$ was negative in gene-tox profile Ames (TA98/100 strains; +/- S9) and micronucleus tests (+/- S9).

Additional in vitro potency data of $\mathbf{2 3}$ is detailed in Table 5. In human whole blood, $\mathbf{2 3}$ demonstrated potent inhibition of anti-IgE stimulated CD63 expression on basophils, with an $\mathrm{EC}_{50}$ of $257 \mathrm{nM}$. Furthermore, 23 inhibited cellular functions in murine and human B cells, as well as human monocytes. Specifically, CD86 induction was reduced after BCR activation in murine $\mathrm{B}$ cells with an $\mathrm{EC}_{50}$ of $91 \mathrm{nM}$. Additionally, 23 strongly inhibited anti-IgM stimulated B-cell proliferation $\left(\mathrm{EC}_{50}=6 \mathrm{nM}\right)$, and immune-complex (IC) triggered cytokine production by human monocytes $\left(\mathrm{EC}_{50}=37 \mathrm{nM}\right.$ [TNF $\alpha$; $\mathrm{EC}_{50}$ $=22 \mathrm{nM}[\mathrm{IL} 1 \beta])$. Consistent with the lack of Btk expression in $\mathrm{T}$ cells and its selectivity profile, 23 did not affect $\mathrm{T}$-cell proliferation $\left(\mathrm{EC}_{50}>5,000 \mathrm{nM}\right)$.

Table 4: Potency and selectivity of $\mathbf{2 3}$ versus other kinases with $>50 \%$ inhibition at $1 \mathrm{uM}$

\begin{tabular}{|c|c|c|c|c|c|c|}
\hline Kinase & BTK & BMX & TEC & FGR & MELK & SRC \\
\hline IC $_{\mathbf{5 0}}$ (nM) & 3 & 14 & 230 & 1033 & $>10000$ & 924 \\
\hline fold vs BTK & --- & $5 \mathrm{x}$ & $77 \mathrm{x}$ & $344 \mathrm{x}$ & $>3333 \mathrm{x}$ & $308 \mathrm{x}$ \\
\hline
\end{tabular}

Table 5: Whole Blood potency, human B-cell proliferation and monocyte cytokine production of $\mathbf{2 3}$

\begin{tabular}{|l|c|}
\hline Assay & $\mathbf{E C}_{\mathbf{5 0}}(\mathbf{n M})$ \\
\hline Whole blood CD63 & 257 \\
\hline Human B-cell proliferation & 6 \\
\hline Human T-cell proliferation & $>5000$ \\
\hline IC-triggered TNF release from monocytes & 37 \\
\hline IC-stim IL-1 $\beta$ release from monocytes & 22 \\
\hline
\end{tabular}

The predicted human clearance of $\mathbf{2 3}$ was moderate (12 $\mathrm{mL} / \mathrm{min} / \mathrm{kg}$ ) and low $(5 \mathrm{~mL} / \mathrm{min} / \mathrm{kg})$ as respectively determined by liver microsome and hepatocyte assessments (Table 6). The in vivo clearances were moderate in mouse $(43 \mathrm{~mL} / \mathrm{min} / \mathrm{kg})$ and $\operatorname{dog}(14 \mathrm{~mL} / \mathrm{min} / \mathrm{kg})$, and low in rat $(5 \mathrm{~mL} / \mathrm{min} / \mathrm{kg})$. Oral bioavailabilities from solution dosing ranged from a low of $26 \%$ (mouse) to a high of $65 \%$ (dog). Notably, the in vivo clearances in mouse, rat and dog more closely aligned with the in vitro hepatocyte clearance data, providing increased confidence that the in vivo human clearance would be consistent with the lower in vitro hepatocyte values rather than to the higher liver microsome values.

Table 6: Preclinical DMPK Profile of $\mathbf{2 3}$

\begin{tabular}{|c|c|c|c|c|}
\hline \multicolumn{5}{|c|}{ Preclinical DMPK Data } \\
\hline \multirow{3}{*}{ Species } & \multicolumn{3}{|c|}{$\begin{array}{l}\text { Predicted hepatic clearance } \\
\qquad(\mathrm{mL} / \mathrm{min} / \mathrm{kg})\end{array}$} & \multirow{3}{*}{$\mathbf{F}^{\mathrm{a}, \mathrm{b}}$} \\
\hline & \multicolumn{2}{|c|}{ in vitro } & \multirow{2}{*}{$\underset{v_{i v o^{c}}}{i n}$} & \\
\hline & $\begin{array}{c}\text { liver } \\
\text { microsomes }\end{array}$ & $\begin{array}{c}\text { liver } \\
\text { hepatocytes }\end{array}$ & & \\
\hline mouse & 56 & 42 & 43 & $34 \%$ \\
\hline rat & 25 & 17 & 5 & $26 \%$ \\
\hline $\operatorname{dog}$ & 24 & 15 & 14 & $65 \%$ \\
\hline cyno & 22 & 16 & 4 & -- \\
\hline human & 12 & 4 & & \\
\hline
\end{tabular}

${ }^{\mathrm{a}} \mathrm{F}=$ oral bioavailability after a $5 \mathrm{mg} / \mathrm{kg}$ dose $(\mathrm{n}=3)$

${ }^{\mathrm{b}} 60 \% \mathrm{PEG} 400 / 15 \% \mathrm{EtOH} / 50 \mathrm{~mm}$ Citrate buffer $(\mathrm{pH} 4.2)^{\mathrm{c}}$ 
Scheme 1: Synthesis of $\mathbf{2 3}$<smiles>O=c1[nH]nc(Cl)cc1Br</smiles>

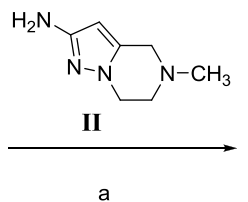

I
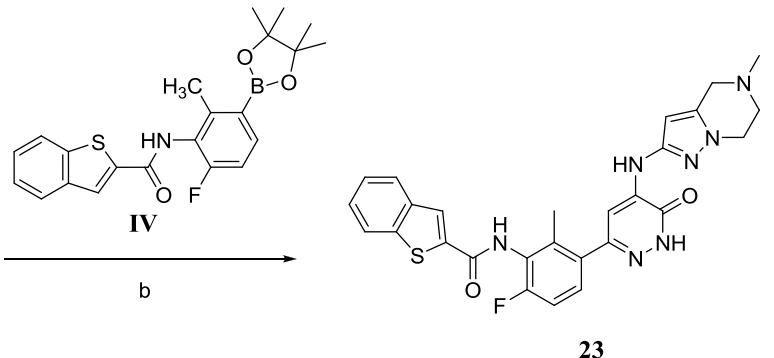

Reagent and conditions: a) $\mathrm{Pd}_{2}(\mathrm{dba})_{3}$, Xantphos, LiHMDS, 1,4-dioxane, THF, reflux, 74\%; b) $\mathrm{Pd}\left(\mathrm{PPh}_{3}\right)_{4}, \mathrm{Na}_{2} \mathrm{CO}_{3}$, DME, $150^{\circ} \mathrm{C}, 50 \%$

The synthesis of $\mathbf{2 3}$ is shown in Scheme $\mathbf{1}$ (details in Supplementary Materials). Starting from 4-bromo-6chloropyridazin-3(2H)-one, Pd-catalyzed C-N coupling (I) with 5-Methyl-4,5,6,7-tetrahydropyrazolo[1,5-a]pyrazin-2-amine (II) gave the coupled product (III) in $74 \%$ yield. Compound III was then converted to $\mathbf{2 3}$ via a Suzuki-Miyaura coupling with IV , in $50 \%$ yield.

In conclusion, several close-in analogs of GDC-0834 (1), such as $15,16 \& 20$, were identified that exhibited improved metabolic stability through the addition of steric hindrance around the acyclic amide bond. These compounds suffered from poor oral bioavailability in rat, as well as other preclinical specie (data not shown). However, a re-design around this scaffold led to the identification of a more potent and stable pyridazinone hinge-binding motif with appreciable oral bioavailability in rat. From this series, compound $\mathbf{2 3}$ was selected as the lead for further profiling.

\section{Acknowledgments}

We thank the BTK team members at Gilead (formerly CGI Pharmaceuticals Inc.), Genentech, ChemPartner, and AMRI for their contributions in generating the data for this manuscript. Use of the Stanford Synchrotron Radiation Lightsource, SLAC National Accelerator Laboratory, is supported by the U.S. Department of Energy, Office of Science, Office of Basic Energy Sciences under Contract No. DE-AC02-76SF00515.

\section{References and notes}

1. Satterthwaite, A. B. and Witte, O. N. Immunol. Rev. 2000, 175, 120127 .

2. Brunne, R. C.; Muëller, B.; Wirth, T. Histol. Histopathol. 2005, 20, 945-955.

3. Di Paolo, J. A.; Huang, T.; Balazs, M.; Barbosa, J.; Barck, K. H.; Bravo, B. J.; Carano, R. A.; Darrow, J.; Davies, D. R.; DeForge, L. E.; Diehl, L.; Ferrando, R.; Gallion, S. L.; Giannetti, A. M.; Gribling, P.; Hurez, V.; Hymowitz, S. G.; Jones, R.; Kropf, J. E.; Lee, W. P.; Maciejewski, P. M.; Mitchell, S. A.; Rong, H.; Staker, B. L.; Whitney, J. A.; Yeh, S.; Young, W. B.; Yu, C.; Zhang, J.; Reif, K.; Currie, K. Nat. Chem. Biol. 2011, 7, 41-50.

4. Puri, K. D., Di Paolo, J.; Gold, M. R. Int. Rev. Immunol. 2013, 32, 397-427.

5. Robak, T. ; Robak, E. Expert Opin. Investig. Drugs 2012, 21, 921 947.

6. Young, W.B.; Barbosa, J.; Blomgren, P.; Bremer, M.C.; Crawford, J.J.; Dambach, D.; Eigenbrot, C.; Gallion, S.; Hymowitz, S. Kropf, J.K.; Le, S.H.; Liu, L.; Lubach, J.; Macaluso, J.; Maciejewski, P.; Maurer, B.; Mitchell, S.; Ortwine, D.; Di Paolo, J.; Reif, K.; Scheerens, H.; Schmitt, A.; Sowell, C.G.; Wang, X.; Wong, H.; Xiong, J.M.; Xu, J.; Zhao, Z.; Currie, K. S., Bioorg. Med. Chem. Lett., accepted.

7. Liu, L.; Halladay, J.; Shin, Y.; Wong, S.; Coraggio, M.; La, H.; Baumgardner, M.; Le, H.; Gopaul, S.; Boggs, J.; Kuebler, P.; Davis, J.; Liao, C.; Lubach, J.; Deese, A.; Sowell, G.; Currie, K.; Young, W.; Khojasteh, C.; Hop, C.; Wong, H. Drug Metab. Dispos., 2011, 39, 1840-9.

8. We later learned that the metabolizing enzyme was aldehyde oxidase (AO) and/or carboxy esterase: Sodhi, J.; Wong, S.; Kirkpatrick D. S.; Liu, L.; Khojasteh, S. C.; Hop, C. E. C. A; Barr, J. T.; Jones, J. P.; Halladay, J. Drug Metab. Dispos., 2015, 43, 908-915.

9. Elagawany, M.; Ghiaty, A.; Ibrahim, M.A.; Abdel-Samii, Z. K.; ElFeky, S. A.; Ahmed, H. E. A.; Bajorath, J. Bioorg. Med. Chem. Lett. 2013, 23, 2007-2013

10. Barbosa, A. J. et. al. WO 2010/056875.

11. Jarboe, J.S.; Dutta, S.; Velu, S.E.; Willey, C.D. Recent Pat. Anticancer Drug Discov. 2013, 3, 228-38.

12. Cenni, B.; Gutmann, S.; Gottar-Guillier, M. Int Rev Immunol. 2012, 2 , 166-73.

13. Schmidt, U.; Boucheron, N. ; Unger, B.; Ellmeier, W. Int Arch Allergy Immunol. 2004, 134, 65-78.

14. Readinger, J.A.; Mueller, K.L.; Venegas, A.M.; Horai, R.; Schwartzberg, P.L. Immunol Rev. 2009, 1, 93-114. 


\section{Graphical Abstract}

Discovery of Potent and Selective Bruton's Tyrosine Kinase Inhibitors: Pyridazinone Analogs with Improved Metabolic Stability

Wendy B. Young, James Barbosa, Peter Blomgren, Meire C. Bremer, James J. Crawford, Donna Dambach, Charles Eigenbrot, Steve Gallion, Adam R. Johnson, Jeffrey E. Kropf, Seung H. Lee, Lichuan Liu, Joseph W. Lubach, Jen Macaluso, Pat Maciejewski, Scott A. Mitchell, Daniel F. Ortwine, Julie Di Paolo, Karin Reif, Heleen Scheerens, Aaron Schmitt, Xiaojing Wang, Harvey Wong, Jin-Ming Xiong, Jianjun Xu, Christine Yu, Zhongdong Zhao and Kevin S. Currie

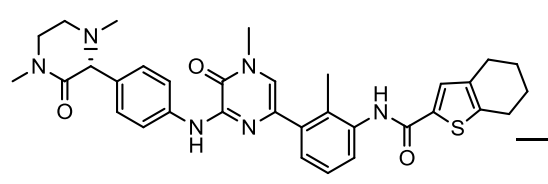

GDC-0834 (1)

\section{Leave this area blank for abstract info.}

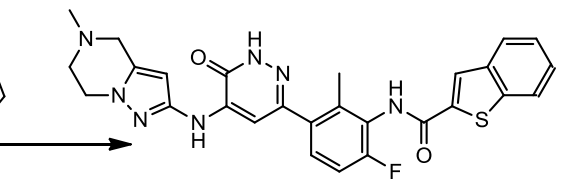

23 